\title{
Assessment of saturation flow at signalized intersections: a synthesis of global perspective and future directions
}

\author{
Satyajit Mondal and Ankit Gupta* \\ Department of Civil Engineering, Indian Institute of Technology (Banaras Hindu University), Varanasi 221005 , India
}

\begin{abstract}
Saturation flow assessment at signalized intersections is one of the key features for analysing various performance measures such as capacity, level of service, signal strategies and coordination, and prediction of traffic flow models. Thus, an accurate estimation of saturation flow value is more beneficial at signalized intersections. Several studies have focused on the estimation of saturation flow in different roadway, traffic and control conditions. Earlier, saturation flow estimation methods were developed purely based on homogeneous traffic, where vehicle interaction was relatively less. However, in mixed traffic, an uneven distribution can be observed due to different vehicle dynamics and manoeuvrability with weak lane discipline. Thus, many studies have been carried out to frame an appropriate saturation flow estimation method. This study presents a comprehensive review on various saturation flow estimation methods developed in different traffic conditions; the drawbacks of the each method are also summarized. Moreover, a list of influencing factors affecting saturation flow value is provided. The general challenges in saturation flow estimation followed by some future direction for improvement in prediction models are also highlighted.
\end{abstract}

Keywords: Estimation method, homogeneous and mixed traffic, influencing factors, saturation flow, signalized intersection.

THE flow characteristics at intersections in developed and developing countries are not the same due to the wide nature of vehicular parameters and behaviour along with varied traffic flow regulation. The traffic stream in most of the Western countries, usually stated as homogeneous traffic with high percentage of vehicles with similar characteristics (typically cars) and less percentage of heavy vehicles, follows proper lane discipline. Whereas the traffic stream in developing countries is purely mixed in nature, having different vehicle classes with wide static and dynamic properties travelling through the same road length without any lane separation. As a result, distinct nature of traffic flows can be observed at signalized intersections due to this basic difference between homogeneous and mixed traffic stream ${ }^{1}$.

*For correspondence. (e-mail: ankit.civ@itbhu.ac.in)
Assessment of saturation flow is an important major input for capacity estimation, traffic management, delay analysis and control measures at signalized intersections. It is defined as a steady-state discharge of queued vehicles from an intersection approach with continuous green signal and an infinite queue ${ }^{2}$. In general, it can be measured by identifying the maximum departure rate of queued vehicles from an intersection approach during green signal under prevailing conditions. Webster ${ }^{3}$ first analysed the saturation flow at signalized intersections and proposed a linear relation of saturation flow with lane width for a homogeneous traffic scenario having no parked vehicles. The US Highway Capacity Manual (HCM) has defined some fundamental attributes related to flow characteristics at signalized intersections ${ }^{4}$. It has also proposed a general procedure for saturation flow estimation using a base flow value for each lane. For mixed traffic, the Indian Roads Congress suggests a basic saturation flow model with respect to approach width ${ }^{5}$. The Indian Highway Capacity Manual ${ }^{6}$ recommends a base saturation flow model for different approach widths followed by implementing three different adjustment according to the traffic scenario.

The varied nature of traffic in different countries significantly encourages researchers to analyse saturation flow and develop saturation flow models according to the prevailing roadway, traffic and control conditions. Continuous research work have been done both in macro- and micro-levels in the accurate estimation of saturation flow value through developing different estimation methods. A few studies highlight various aspects related to saturation flow such as influencing factors, suitable methods, etc. but have failed to deliver details for both homogeneous and mixed traffic streams ${ }^{7,8}$. The parameters influencing saturation flow value are different at different locations and also vary with the nature of traffic. Thus, we need to review the factors affecting saturation flow and also various estimation methods suitable for different traffic conditions.

\section{Parameters affecting saturation flow}

Parameters affecting the saturation flow value are different at different traffic and roadway facilities. Researchers 
REVIEW ARTICLES

Table 1. Factors considered in various guidelines for saturation flow estimation

\begin{tabular}{|c|c|c|c|}
\hline Guideline & Country & Parameters included & Critical comments \\
\hline ARRB 1968 (ref. 9) & Australia & $\begin{array}{l}\mathrm{AW}, \mathrm{AG}, \mathrm{IG}, \mathrm{VT}, \mathrm{TV}, \mathrm{PC}, \mathrm{BS}, \mathrm{LU} \text {, } \\
\mathrm{WC}\end{array}$ & $\begin{array}{l}\text { The ARRB considered all possible influencing } \\
\text { factors in saturation flow estimation. Only signal } \\
\text { parameters were not considered due to less } \\
\text { variability in signal characteristics. }\end{array}$ \\
\hline IHCM 1993 (ref. 10) & Indonesia & $\mathrm{AW}, \mathrm{AG}, \mathrm{TV}, \mathrm{WC}$ & $\begin{array}{l}\text { The IHCM analysed and proposed a few } \\
\text { parameters. However, a mixed nature of traffic } \\
\text { can be observed, where several influencing } \\
\text { factors could affect the saturation flow value. }\end{array}$ \\
\hline IRC SP: 41-1994 (ref. 5) & India & $\mathrm{AW}, \mathrm{AG}, \mathrm{VT}, \mathrm{TV}, \mathrm{ST}$ & $\begin{array}{l}\text { This is the first guideline proposed earlier for } \\
\text { representing Indian traffic scenario at a } \\
\text { signalized intersection. Thus, few parameters } \\
\text { related to roadway and traffic were included. }\end{array}$ \\
\hline FHCM 2002 (ref. 11) & Finland & $\mathrm{AW}, \mathrm{IG}, \mathrm{VT}, \mathrm{TV}, \mathrm{PC}, \mathrm{ST}$ & $\begin{array}{l}\text { This guideline does not consider the effect of side } \\
\text { friction or vehicle activities (such as near-side or } \\
\text { far-side bus stop) for analysing the saturation } \\
\text { flow value. These parameters significantly affect } \\
\text { the saturation flow value as it interrupts the nor- } \\
\text { mal flow condition due to blockage. }\end{array}$ \\
\hline MHCM 2006 (ref. 12) & Malaysia & $\mathrm{AW}, \mathrm{AG}, \mathrm{IG}, \mathrm{VT}, \mathrm{TV}, \mathrm{PA}, \mathrm{BS}$ & $\begin{array}{l}\text { The MHCM does not consider the influence of } \\
\text { pedestrian activities and signal characteristics on } \\
\text { saturation flow value. Being a developing } \\
\text { country, vehicle-pedestrian interaction is a } \\
\text { common phenomenon in Malaysia, usually } \\
\text { observed at signalized intersections. }\end{array}$ \\
\hline HCM 2010 (ref. 4) & USA & $\mathrm{AW}, \mathrm{AG}, \mathrm{VT}, \mathrm{TV}, \mathrm{PC}, \mathrm{PA}, \mathrm{BS}, \mathrm{LU}$ & $\begin{array}{l}\text { The provisions of this guideline are adopted by } \\
\text { different countries to propose their design } \\
\text { aspects. However, this guideline does not } \\
\text { considered the effect of signal timing and } \\
\text { weather conditions, which are found to be } \\
\text { critical in most of the countries. }\end{array}$ \\
\hline THCM 2011 (ref. 13) & Taiwan & AG, IG, VT, TV, PC, PA, BS, ST & $\begin{array}{l}\text { The THCM included almost all the significant } \\
\text { factors that can be found in most of the } \\
\text { developing countries with mixed traffic situation. } \\
\text { No such provision can be found to analyse the } \\
\text { effect of approach width on saturation flow } \\
\text { value. }\end{array}$ \\
\hline FGSV 2015 (ref. 14) & Germany & $\mathrm{AW}, \mathrm{AG}, \mathrm{IG}, \mathrm{VT}, \mathrm{PC}$ & $\begin{array}{l}\text { This guideline only considered few adjustment } \\
\text { factors related to roadway and traffic conditions. } \\
\text { However, various blockage factors for parking } \\
\text { and bus activities at intersections are not } \\
\text { included. }\end{array}$ \\
\hline Indo-HCM 2017 (ref. 6) & India & AW, VT, TV, BS, ST & $\begin{array}{l}\text { This is the newly developed guideline proposed for } \\
\text { analysing the Indian traffic scenario. However, } \\
\text { the model proposed for saturation flow } \\
\text { estimation only considers a few adjustments } \\
\text { factors. }\end{array}$ \\
\hline
\end{tabular}

AW, Approach width; AG, Approach gradient; IG, Intersection geometry; VT, Vehicle type; TV, Turning vehicle; PC, Pedestrian crossing; PA, Parking activity; BS, Bus stop; LU, Lane utilization; ST, Signal time; WC, Weather condition.

from both developed and developing countries have found various factors associated with saturation flow and categorized them into three classes, viz. roadway conditions, traffic conditions and control and other conditions. Various guidelines developed for analysing traffic characteristics of the prevailing situation in different countries have highlighted several influencing factors that significantly affect the saturation flow value. The HCM has enlisted a total of 12 factors for analysing flow characteristics at signalized intersections ${ }^{4}$. Whereas some guidelines for developing countries have incorporated only few factors depending upon the roadway and traffic facility. Table 1 shows the different factors discussed in various manuals and guidelines proposed by several countries to analyse saturation flow value at signal controlled intersections. 
REVIEW ARTICLES

Table 2. Parameters affecting saturation flow value

\begin{tabular}{|c|c|c|}
\hline Parameters & Inferences & Reference \\
\hline Approach width & $\begin{array}{l}\text { The saturation flow value increases with increase in approach lane width. Majority of the } \\
\text { studies have found a linear relationship between saturation flow and approach lane } \\
\text { width. }\end{array}$ & $12,13,22$ \\
\hline Type of lane & $\begin{array}{l}\text { The saturation flow significantly reduces with the presence of upstream short lane. } \\
\text { An optimum cycle length has to be proposed to obtain maximum capacity when } \\
\text { upstream short lane exists. Also, shared lanes at intersections show significant } \\
\text { improvement in saturation flow value. }\end{array}$ & $17,18,47$ \\
\hline Number of lanes & $\begin{array}{l}\text { Saturation flow is improved by } 4.3 \% \text { for three-lane configured approaches with respect to } \\
\text { two-lane configured approaches. In some cases it may increase up to } 25 \% \text { for each } \\
\text { additional through traffic lane. }\end{array}$ & 14,15 \\
\hline Approach grade & $\begin{array}{l}\text { When the approach grade is more than } 2 \% \text {, the saturation flow value will increase } \\
\text { significantly with percentage increase of approach grade. }\end{array}$ & 22 \\
\hline Turning radius & $\begin{array}{l}\text { The saturation flow value becomes more close to the base value with increase in turning } \\
\text { radius. }\end{array}$ & 22 \\
\hline U-turn operation & $\begin{array}{l}\text { The saturation flow value reduces when the percentage of U-turning vehicles is relatively } \\
\text { high (more than } 40 \text { ). In addition, the effect of U-turn operation on saturation flow } \\
\text { value increases with the increase in percentage of U-turning vehicles in left-turn lane. }\end{array}$ & 21 \\
\hline Flow characteristics & $\begin{array}{l}\text { Higher percentage of two-wheelers in the traffic stream blocks the available area for } \\
\text { vehicle movement, leading to a reduction in saturation flow value. Whereas, an } \\
\text { increase in the proportion of larger vehicles results in higher saturation flow due to } \\
\text { more lane disciplined flow. }\end{array}$ & 2 \\
\hline $\begin{array}{l}\text { Presence of } \\
\text { motorcycles }\end{array}$ & $\begin{array}{l}\text { The headways of vehicles are different and corresponding to the start-up, lost time } \\
\text { increases nonlinearly when the number of motorcycles increases in front of the queue. } \\
\text { A low saturation headway with a high share of motorcycles. }\end{array}$ & $25-29$ \\
\hline $\begin{array}{l}\text { Percentage of heavy } \\
\text { vehicles }\end{array}$ & $\begin{array}{l}\text { Saturation flow value changes inversely with increase in percentage of heavy vehicles } \\
\text { and the number of stops made by vehicles around the intersection. A } 40 \% \text { share of } \\
\text { heavy vehicles in the traffic stream reduces the saturation flow value up to } 30 \% \text {, which } \\
\text { is lower than the US HCM (2010) recommendations. }\end{array}$ & $30-32$ \\
\hline Vehicle blockage & $\begin{array}{l}\text { A modified passanger can unit (PCU) is identified to represent non-conventional local } \\
\text { public transport vehicles, and also adjusts the bus blockage time to reflect the present } \\
\text { traffic situation. }\end{array}$ & $33-35$ \\
\hline Presence of bicycles & $\begin{array}{l}\text { The presence of bicycles on saturation flow is analysed using the total occupancy, which } \\
\text { is evaluated through bicycles and their proportion in right turn lane groups. }\end{array}$ & 36 \\
\hline Pedestrians crossing & $\begin{array}{l}\text { An occupancy-saturation flow relationship is established for determining the relevant } \\
\text { level of conflict-zone occupancy that effects a reduction in turning saturation flow. }\end{array}$ & 37 \\
\hline Parking activity & $\begin{array}{l}\text { The service rate reduction for an under-saturated intersection might be higher when a } \\
\text { vehicle is parked before it joins the queue at the red signal. The flow value reduction is } \\
\text { always higher when the cars park after they discharge from the queue. }\end{array}$ & 35,38 \\
\hline Signal characteristics & $\begin{array}{l}\text { The start-up lost time is improved significantly and reduced by around } 33 \% \text { due to the } \\
\text { installation of countdown signal characteristics. }\end{array}$ & $39-42$ \\
\hline Weather conditions & $\begin{array}{l}\text { Saturation flow changes significantly under different weather conditions, such as sunny, } \\
\text { cloudy, dry and wet roadway surface, short and long duration of rainfall and snowfall. } \\
\text { The rate of reduction in saturation flow value for long-duration rainfall is about } 8.5 \%- \\
12.3 \% \text {; the } 3.6 \% \text { for short-duration rainfall, } 10 \% \text { for snowfall (wet roadway surface) } \\
\text { and } 11.4 \% \text { for cloudy or foggy weather with a dry roadway surface. }\end{array}$ & $43-46$ \\
\hline Area types & $\begin{array}{l}\text { The different saturation headway values are observed both for recreational area and area } \\
\text { with left and through movements. An adjustment factor value of } 0.92 \text { is defined for } \\
\text { recreational areas and } 1.0 \text { for other areas. }\end{array}$ & 14 \\
\hline
\end{tabular}

Moreover, many studies both from developed and developing countries have identified various factors affecting saturation flow such as approach width ${ }^{9-14}$, number of lanes ${ }^{15,16}$, type of lane ${ }^{17-21}$, approach grade ${ }^{22}$, U-turn operation ${ }^{17,21}$, turning radius ${ }^{22}$, flow characteris$\operatorname{tics}^{23,24}$, presence of motorcycles ${ }^{25-29}$, percentage of heavy vehicles ${ }^{30-32}$, blockage due to vehicles ${ }^{33-35}$, presence of bicycle ${ }^{36}$, pedestrian crossing ${ }^{37}$, parking acti- vity $^{35,38}$, signal characteristics ${ }^{39-42}$, weather conditions ${ }^{43-46}$ and different area types ${ }^{47}$. A significant outcome has been summarized by each of the studies for different traffic facility types. It is inferred that each of the factors needs to be considered while analysing saturation flow under prevailing roadway and traffic facility types. Table 2 shows the significant outcomes underlined by various researchers while analysing the different parameters 
affecting saturation flow at different traffic and roadway facilities.

\section{Methods for saturation flow estimation}

Saturation flow is a macro-level performance measuring parameter that usually indicates the operational characteristics of a signal-controlled intersection. It is a useful parameter to estimate various intersection characteristics and performance measures. At a signalized intersection, vehicles stop at the intersection area along the approach width during red signal and start dissipating when the signal changes to green. A number of methods were developed to estimate the saturation flow value at signalized intersections both for homogeneous and mixed traffic situations. A detailed discussion of each method is presented here.

\section{Headway ratio method}

Earlier studies related to saturation flow estimation focused on using headway ratio method ${ }^{48-50}$. The basic assumption of this method is that the headways of successive vehicles become constant after the departure of the first four vehicles in the queue. The saturation headway is the primary input of this method to estimate saturation flow value at signalized intersection ${ }^{51}$. Saturation headway is defined as the headway of the vehicles in a steady-state platoon movement passing through an intersection during green signal. A stable platoon movement is a group of vehicles that are travelling with similar speed characteristics. The headway of the first four vehicles has a higher value due to driver reaction time, which occurs in the first few seconds of green time. Thus, the saturation headway is not obtained up to the fourth vehicle position in the queue ${ }^{17,40,52}$.

Thus, if $H_{i}^{\mathrm{a}}$ denotes the average headway of vehicles from $i$ th position of vehicle to the last vehicle in the queue $(q)$ for $x$ th cycle, then

$$
H_{i}^{\mathrm{a}}=\frac{\sum_{x=1}^{C} \sum_{i=1}^{q} H_{i x}}{\sum_{x=1}^{C} \sum_{x=1}^{C} i} .
$$

Therefore, for a given traffic situation, if $h_{\mathrm{s}}$ is the saturation headways ( $\mathrm{sec}$ ), then the corresponding saturation flow value can be estimated using the following relationship

$$
\mathrm{s}=\frac{3600}{h_{\mathrm{s}}},
$$

where $\mathrm{s}$ is the saturation flow value (vehicles/h).

\section{HCM methodology}

The HCM provides a general procedure for estimating saturation flow value at signalized intersections ${ }^{4}$. The proposed methodology that includes a base saturation flow and various adjustment factors to account for the effect of different roadway and traffic conditions is represented in eq. (3).

$$
S=s_{0} N f_{\mathrm{W}} f_{\mathrm{HV}} f_{\mathrm{g}} f_{\mathrm{e}} f_{\mathrm{bb}} f_{\mathrm{a}} f_{\mathrm{LU}} f_{\mathrm{LT}} f_{\mathrm{RT}} f_{\mathrm{Lpb}} f_{\mathrm{Rpb}},
$$

where $S$ represents the saturation flow (vehicles $/ \mathrm{h}$ ); $s_{0}$ the base saturation flow value which is 1900 passenger cars/h based on the saturation headway of vehicles obtained after the departure of the first five vehicles; $N$ is the number of lanes in the selected approach, and there are 11 different adjustment factors related to various roadway and traffic conditions such as approach lane width, proportion of heavy vehicles, percentage of approach grade, nearby parking activity, blockage due to bus operation, type of area, percentage utilization of lane, left-turn operation, right-turn operation, pedestrians left-turn and rightturn activity at the intersection respectively. Each adjustment factor is thoroughly discussed in the $\mathrm{HCM}^{4}$, and possible methodologies are mentioned to account for their effects on saturation flow value.

As the method proposed in $\mathrm{HCM}^{4}$ is solely based on homogeneous traffic conditions, therefore a number studies have analysed the different factors affecting saturation flow in mixed traffic situation. Chen et al. ${ }^{53}$ analysed the effect of pedestrian activity characteristics such as pedestrian behaviour, pedestrian-vehicle interaction and pedestrian arrival on the capacity of right turning movement at signalized intersections. They also proposed a model to incorporate these three factors on flow characteristics. Shao et al. $^{22}$ analysed the effect of lane width, approach grade, traffic composition and left turn radius on saturation flow value. A saturation flow model was proposed similar to the HCM model for analysing the above influencing parameters. Chen et al. ${ }^{17}$ proposed saturation flow model based on percentage of lane blockage, approach gradient, queue length and percentage of turning traffic for shared left-turn lanes at signalized intersections. Lila et $a l^{27}$ and Anusha et al. ${ }^{54}$ studied the effect of percentage of motorized two-wheelers on saturation flow value, and a new adjustment factor based on percentage of motorized two-wheelers was proposed to be incorporated in the HCM model. Tuffour et al. ${ }^{33}$ studied the bus blockage time appropriate to local public transport vehicles and introduced an empirical expression to adjusting for bus blockage in the HCM saturation flow model.

\section{TRL method}

It is one of the simple methods for estimating saturation flow value at signalized intersections. In this method, 


\section{REVIEW ARTICLES}

classified vehicles count is considered for three consecutive saturated green intervals. Then the saturation flow can be estimated as the number of vehicles travelled in the middle interval divided by the length of the middle interval. Kimber et $a l .{ }^{55}$ estimated the saturation flow value for multilane approaches using the TRL method and found that saturation flow increased nonlinearly with the approach width. Williams and Griffiths ${ }^{56}$ utilized the TRL method to estimate saturation flow value. They considered the classified vehicles count over the stop line for $6 \mathrm{sec}$ intervals during the green and amber period of the cycles under saturated flow condition. Later, Turner and Harahap $^{57}$ estimated saturation flow value by modifying the basic TRL method for suitable application at signalcontrolled intersections.

\section{Regression method}

This is one of the useful soft-computing tools involved in developing relationships between variables. Therefore, it is necessary to identify the significant parameters that influence the dependent variables. Various studies utilized the regression method to develop models between various influencing parameters and saturation flow. Branston and Gipps ${ }^{58}$ analysed the effect of vehicle type, green time and lost time on saturation flow using two multiple regression methods. Bhattacharya and Bhattacharya $^{11}$ suggested a simple linear relation to calculate the saturation flow value at different approach width conditions. Minh and Sano ${ }^{25}$ studied the effect of motorcycles on saturation flow through developing a linear relationship between saturation flow, lane width and the number of motorcycles passing the stop line. Chand et $a l .{ }^{59}$ analysed the effect of various approach widths on saturation flow under mixed traffic. Also, a regression model was developed between saturation flow and percentage of two-wheelers and cars to understand the saturation flow variation at different green intervals. Moreover, a number of studies have shown that the regression method can be used to examine the effect of various factors on saturation flow value $\mathrm{e}^{7,14,36,60-62}$. Radhakrishnan and Mathew ${ }^{63}$ proposed a saturation flow model for mixed traffic with respect to different percentage of vehicle share in the traffic stream. Saha et al. ${ }^{64}$ developed a saturation flow model by considering the through traffic and right-turning traffic for mixed traffic situation. Yadav and Marsani ${ }^{65}$ formulated a linear relationship between the effect of approach width, approach grad and rightturn radius on saturation flow value. Ramireddy et al. ${ }^{66}$ analysed the effect of encroaching vehicles on saturation flow using a multilinear regression method.

\section{Optimization method}

In the field of transportation, optimization technique is one of the useful operations to solve critical problems.
Various transportation problems have been solved using the optimization method, where the usual traditional methods have been found unsuitable for appropriate solutions. Radhakrishnan and Mathew ${ }^{63}$ proposed an optimization method through minimizing Theil's as an objective function as shown in below.

$$
\begin{aligned}
& \text { Minimize } z=\frac{\sqrt{\frac{1}{N} \sum_{i=1}^{N}\left(s_{\mathrm{b}}-s_{i}^{\mathrm{e}}\right)^{2}}}{\sqrt{\frac{1}{N} \sum_{i=1}^{N}\left(s_{\mathrm{b}}\right)^{2}}+\sqrt{\frac{1}{N} \sum_{i=1}^{N}\left(s_{i}^{\mathrm{e}}\right)^{2}}}, \\
& s_{i}^{e}=\sum_{j} n_{j} p_{j}
\end{aligned}
$$

such that $p_{j} \geq p_{j \min }$,

where $z$ is the Theil's coefficient, $s_{\mathrm{b}}$ the base saturation flow (passanger car unit $(\mathrm{PCU}) / \mathrm{h}), s_{i}^{\mathrm{e}}$ the estimated saturation flow for $i$ th interval, and $n_{j}$ and $p_{j}$ are the number of vehicles and its PCU value respectively.

Majhi $^{67}$ developed an optimization method to estimate saturation flow at signalized intersections through minimizing the difference between the flat portion of an ideal saturation flow curve and the observed saturation flow from the field. The proposed objective function is

$$
\text { Minimize } z=\sqrt{\frac{1}{n}} \sum_{i=2}^{n} \sum_{j=1}^{m}\left(x-y_{i}^{j} p^{i}\right)^{2},
$$

such that $p_{\min }^{j} \leq p^{j} \leq p_{\max }^{j}$,

where $n$ is the number of saturation periods, $p^{j}$ the passenger car equivalent of vehicle type $j, m$ the vehicle type, $y$ the number of vehicles of type $j$ and $x$ is the base saturation flow value.

Mondal et al. ${ }^{24}$ proposed an optimization process that considers the flow during saturated green interval and includes it in the overall optimization process, which helps reduce the initial surge effect due to smaller vehicles during the first few seconds of green time interval. In addition, they also established that reducing the high flow value for mixed traffic, an explicit demonstration can be made in the optimization process for PCU estimation of each vehicle category in the mixed stream.

\section{Simulation method}

Real-life observations should be made in a complete range of traffic and roadway features for performance evaluation at signalized intersections. Such a procedure 
using analytical or traditional methods would be tedious as well as time-consuming for analysing such complex relationships. Thus, simulation approach is considered to analyse various types of traffic behaviour in a complex situation. The simulation method provides a quick response to abstract a traffic scenario using an appropriate calibration and validation procedure ${ }^{68-71}$. Several microsimulation methods have been proposed such as MIXNETSIM $^{72}$, VISSIM $^{73,74}$, SimTraffic $^{73}$, CORSIM $^{73,75}$, HETEROSIM $^{76}$ and AIMSUN ${ }^{77}$ to analyse traffic flow behaviour at signalized intersections. Earlier, models in micro-simulation approaches were informally developed and proposed with default parameter values without any proper calibration results in erroneous simulation output $^{78}$. Thereafter, researchers have found that every simulation model needs a systematic calibration process for reasonable model development ${ }^{69,79-81}$. A number of suitable methodologies have been proposed for the calibration of the simulation model ${ }^{81-84}$. A simple methodological approach was developed to perform the calibration of a simulation model using the software VISSIM under homogeneous traffic conditions ${ }^{81}$. Schultz and Rilett ${ }^{85}$ suggested a calibration process for motor-vehicle distribution using CORSIM. Parameter optimization is a useful calibration technique that uses using various mathematical algorithms. Genetic algorithm is extensively used by researchers for solving optimization problems related to simulation calibration ${ }^{84,86-88}$. Calibration and model validation are done by comparing the traffic parameters obtained from simulation outputs with the field results. Several traffic parameters such as vehicle delay, headway, travel time and speed are considered as crucial elements for evaluation of simulation output. Delay is a useful measure of effectiveness (MOE) to evaluate the model performance developed in various simulation tools such as VISSIM, CORSIM and AIMSUN ${ }^{84,87,89}$. Whereas travel time and speed of vehicles are also considered in various simulation approaches for performance evaluation of the model ${ }^{81,90}$. In the present study, saturation flow, one of the useful performance measures of an intersection is considered as the MOE in the evaluation of the simulation model.

\section{Other methods}

In addition to the above listed methods for saturation flow estimation at signalized intersections, a few estimation methods have been explored by researchers in different traffic flow scenarios. Mohan and Chandra ${ }^{91}$ proposed a queue clearance-based method for estimating saturation flow value through estimating passenger car unit value. This method considers the queue clearance rate (QCR) as the ratio of the number of vehicles in the queue to the time taken by the queue to clear the conflict area

$$
\begin{aligned}
& \mathrm{QCR}=\frac{N}{T}, \\
& N=\sum_{j=1}^{k} n_{j} \frac{w_{\mathrm{car}}}{w_{j}} \mathrm{PCE}_{j},
\end{aligned}
$$

where $w_{\text {car }}$ is the width of standard vehicle (car), $w_{j}$ the width of vehicle type $j, \mathrm{PCE}_{j}$ the equivalent value of vehicle type $j$ and $k$ stands is the vehicle category.

Biswas et al. ${ }^{92}$ developed a kriging-based approach to analyse the saturation flow value. This method was also used to analyse various adjustment factors such as approach width and right-turn movement of shared lane on saturation flow value. In continuation, Saha et al. ${ }^{93}$ adopted the kriging-based method to analyse saturation flow value for Indian mixed traffic scenario.

$\mathrm{Wu}^{94}$ introduced an additive conflict flow theory by considering individual traffic streams and their conflict groups for estimating intersection capacity. Li et al. ${ }^{95}$ adopted this method to analyse and develop a saturation flow model at three different traffic flow conditions for a multi-lane signalized intersection. Gap acceptance theory is one of the useful approaches suitable for analysing several types of traffic behaviour at unsignalized interactions, although some studies have been found it useful for evaluating various traffic parameters at signalized intersections ${ }^{96-100}$.

Preethi and Ashalatha ${ }^{101}$ suggested a new approach for estimating saturation flow under mixed traffic based on area occupancy. They estimated the equivalent number of car occupancies in the intersection area $\left(N_{\mathrm{cs}}\right)$ for saturation flow estimation based on the equivalent homogeneous traffic stream area and occupancy time of standard cars during saturated green interval.

\section{Summary of saturation flow estimation methods}

An overview of various saturation flow estimation methods for different traffic scenarios has been presented in the previous section. It can be observed that researchers proposed different methods and used several parameters for analysing and developing saturation flow models both for homogeneous and mixed traffic streams. The studies carried out in the initial stages were based on headway ratio method $^{10,48,49}$ and TRL method ${ }^{55-57}$, suitable for developed countries with homogeneous traffic stream, where cars dominated the traffic flow. Some studies adopted the headway ratio method to estimate saturation flow value at signalized intersections under mixed traffic stream and provided satisfactory results ${ }^{102-104}$. However, the main drawback was that the headway ratio method is only applicable for a steady-state traffic scenario. While for an unsteady traffic environment, the estimation of headway is difficult with high erroneous result. Also, it is 
challenging to extract the headway value of all the vehicles for weak lane disciplined mixed traffic stream as vehicles do not follow proper lane discipline. The method considers the flow values of three saturated cycles for estimating saturation flow value. But for weak lane disciplined mixed traffic situation, the flow value at an intersection varies significantly at different cycles due to uneven distribution of traffic while departing. The HCM proposed a detailed methodology for evaluating saturation flow value along with various adjustment factors affecting it $^{4}$. Various researchers both from developed and developing countries have found it more suitable than headway ratio and TRL method. Rahman et al. ${ }^{105}$ concluded that the method proposed in the $\mathrm{HCM}^{4}$ would overestimate or underestimate the saturation flow value based on field data under mixed traffic conditions. The HCM methodology ${ }^{4}$ is solely appropriate for homogeneous traffic conditions and less suitable for mixed traffic stream, where the nature of traffic movement is totally different compared to the homogeneous traffic. Also, the HCM method ${ }^{4}$ does not consider the effect of individual vehicle category, which is more effective for mixed traffic stream where vehicles usually travel through gaps without maintaining proper lane discipline. The regression method has been effectively used by various researchers at different traffic scenarios to develop saturation flow models with respect to various influencing factors $7,14,36,60-63$. However, the major drawback of this method is the accuracy level. In most of studies, saturation flow models are found to be linear in nature incorporating few influencing parameters. Thus, there is a high chance of obtaining inaccurate results under different traffic conditions. A few researchers have utilized the optimization method for saturation flow estimation ${ }^{24,63,67}$, where this method is found more suitable with respect to HCM and other methods. The simulation method is widely used as a potential tool to analyse saturation flow at different traffic operations ${ }^{69,79-81,84,86-88}$. Each study involves calibration of vehicular parameters to reflect the actual traffic behaviour according to the field conditions. Nonetheless, the major disadvantage is its suitability in diverse traffic situation while applying the simulation model. In addition, some methods like the optimization method, kriging-based approach and area occupancy method have been developed especially for mixed traffic stream, and are found suitable for evaluating saturation flow value at signalized intersections.

\section{Various challenges in saturation flow estimation}

A number of studies have analysed saturation flow value, including various factors affecting it. In this section, various challenges in estimating saturation flow at signalized intersections are discussed.

\section{Selection of study location}

Selection of suitable site is the foremost criterion for estimating saturation flow value. Saturation flow is different for different intersection classes (three-legged, four-legged or multi-legged) with various approach-lane configurations. The geometric features of an intersection significantly affect the saturation flow value.

\section{Data collection and extraction}

Data collection and extraction are the most challenging aspects for saturation flow estimation. Several data collection procedures are available such as automatic data collection, videographic technique (using video camera, drone or UAV) ${ }^{106,107}$, GPS device ${ }^{108}$, sensors ${ }^{109}$ and loop detectors ${ }^{110}$. However, each process has its own limitations in collecting traffic data from the field. Automatic data collection is a sophisticated and expensive process, and few automatic sensors are available for data collection. While the video-recording process is easier and affordable, the major issues are placing of camera, parallax effect, occlusion and distortion due to the capturing angle during field data collection. Also, headlight glaring of approaching vehicles during data collection at night significantly affects the traffic data. Bluetooth sensors and GPS devices are effective for traffic data collection. Although the sensors may provide an accurate measure of classified traffic volume count for mixed traffic situations, blue tooth sensors or GPS devices are quite inadequate due to unavailability of blue tooth transmitters and difficulty in installing GPS device in each vehicle type travelling through the intersection. While extracting various traffic characteristics, it is essential to classify the existing traffic into various vehicle classes especially for mixed traffic situation as the vehicle category creates a hindrance in saturation flow analysis. Thus, Indo-HCM has proposed a list of vehicle classes and types according to vehicle static and dynamic properties ${ }^{6}$.

\section{Selection of methodology}

Various approaches have been developed both for homogeneous and mixed traffic streams for estimating saturation flow value. Rahman et al. ${ }^{105}$ found that the HCM method overestimates saturation flow value when compared with the traditional headway method. Biswas et $a l .^{92}$ proposed that kriging-based approach gives less erroneous result with respect to headway ratio and regression methods. Also, the same method at different locations with diverse traffic scenarios gives distinct results. Therefore, choice of the appropriate method is a major concern for saturation flow estimation. 


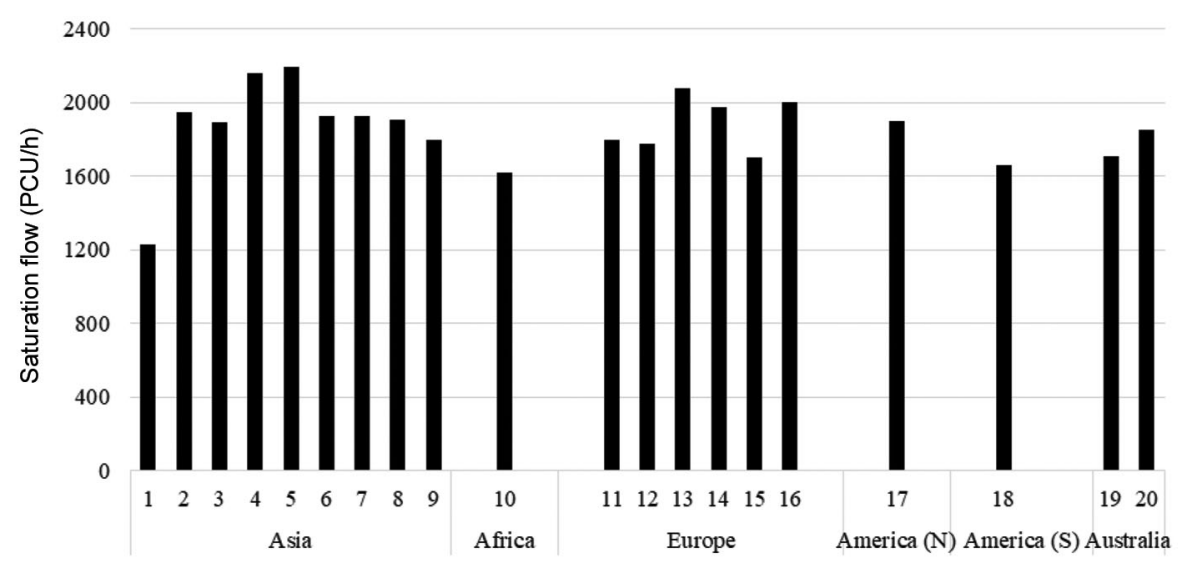

Figure 1. Saturation flow value in different continents. 1. Bhattacharya and Bhattacharya ${ }^{11} .2$. Hussain ${ }^{11} .3$. IRC SP41: 1994 (ref. 5). 4. IHCM 1997 (ref. 117). 5. Arasan and Vedagiri ${ }^{71}$. 6. MHCM 2006 (ref. 119). 7. Radhakrishna and Mathew ${ }^{63} .8$. THCM 2011 (ref. 120). 9. Shao et al..$^{22}$. 10. Hussayin and Shoukry ${ }^{112} .11$. Webster and Cobbe $^{48} .12$. Branston ${ }^{113}$. 13. Kimber et al. ${ }^{55}$. 14. Highway Engineering Laboratory Athens 1990 (ref. 114). 15. Finnish Capacity Manual (ref. 118). 16. German HCM (HBS 2015) ${ }^{121}$. 17. HCM 2010 (ref. 4). 18. De Andrade (J. P. De Andrade, unpublished). 19. Miller ${ }^{10}$. 20. Austroads 1988 (ref. 115).

\section{Factors affecting saturation flow}

Saturation flow is influenced by various factors depending upon the roadway, traffic and control conditions. Table 2 highlights the different factors affecting saturation flow value. Those factors need to be incorporated while estimating saturation flow. Researchers from various countries have found different saturation flow values with respect to various traffic and roadway conditions. Even, within the same country, a distinct value is proposed in different studies and guidelines. Figure 1 shows the saturation flow value obtained by various researchers in different continents.

\section{Conclusion and future direction}

The present study is a comprehensive review on various aspects related to saturation flow estimation at signalized intersections. Various studies focused on analysing saturation flow under different traffic conditions are critically reviewed and presented here. We also highlight major factors related to roadway, traffic and control facilities that affect saturation flow value. A list of such factors included in different guidelines proposed by various countries is presented. This study also discusses in detail the various methods proposed both for homogeneous and heterogeneous traffic conditions. The advantages and disadvantages of each existing method are also highlighted. Thus, the significant findings of the present study can be summarized as follows:

(1) Parameters affecting saturation flow value are different both for developed and developing countries due to distinct traffic culture.

(2) Methodologies proposed for homogeneous traffic conditions are less suitable for heterogeneous traffic.
(3) Estimation of saturation flow for mixed traffic is quite difficult due to a variety of vehicles with different variabilities and their weak lane discipline characteristics.

(4) Regression-based saturation flow models are less suitable due to the linear relationship with the influence parameters.

(5) Simulation application for saturation flow estimation is practically location-based. Application of simulation model parameters for other scenarios is questionable.

In addition, this study presents few future directions based on a critical review of previous studies are as follows:

(1) The accurate estimation of saturation flow depends on the quality and quantity of data that represent the exact traffic behaviour through an intersection. The lack of data is one of the major issues, especially for mixed traffic stream where vehicle behaviour is more critical. Also, video-recording process is widely used which needs more efforts for data collection and extraction from the recorded video. At times it is difficult to extract exact data from the collected video due to uneven distribution and weak lane disciplined mixed traffic stream. Thus, new technologies such as drones/UAVs may be used to collect images of traffic flow at all directions and infer the characteristics of each vehicle type. This way there will be a more detailed understanding of the traffic flow of each vehicle type.

(2) A number of methodologies have been proposed for saturation flow estimation both for homogeneous and mixed traffic streams. Headway ratio, TRL and HCM methods are truly based on homogeneous traffic. While regression and simulation methods are majorly locationbased approaches. The model proposed using the two methods for a particular location may not give an 


\section{REVIEW ARTICLES}

accurate estimation for another location. Optimization and other approaches are explored less as an estimation method. Thus, a gap in the literature is to frame a suitable method for estimating saturation flow value, especially for mixed traffic stream.

(3) Saturation flow varies significantly with location and time. The past studies do not discuss how transferable the saturation flow values are across different cities, different times of the day and days of the week. This may help the transportation engineer to design the intersection geometry and control strategies effectively.

(4) Prediction of saturation flow model is crucial for mixed traffic stream. Most of the predicted models are either based on lane properties or traffic composition with a linear relationship with saturation flow value. Although in a mixed traffic condition, various factors affect saturation flow significantly, which are eliminated due to complex traffic situation. Thus, there is need to develop a combined model with different significant factors affecting saturation flow value.

(5) The use of PCU impairs the understanding of traffic dynamics in mixed traffic environment. A number of methods have been developed to find PCU values, where most of the time researchers have proposed a static unit of each vehicle. In fact, dynamic PCUs might be a good representative of mixed traffic flow conditions. Also, in most of the countries, electric vehicles, automated vehicles or future vehicles can be observed in the traffic stream. Their influence on several traffic flow characteristics at intersections needs to be evaluated.

(6) Various simulation applications on saturation flow prediction have been evaluated for different traffic situations with numerous undefined traffic parameters. In such a scenario, application of agent-based simulation could be reliable to capture vehicle heterogeneity and carfollowing characteristics at a more detailed level.

1. Mondal, S., Chakraborty, S., Roy, S. and Gupta, A., Estimation of passenger car unit for heterogeneous traffic stream of urban arterials, case study Kolkata. Transp. Lett., 2017, 1-13; doi:10.1080/19427867.2017.1293313.

2. Mondal, S. and Gupta, A., Discharge characteristics analysis of queued-up vehicles at signal controlled intersections under heterogeneous traffic conditions. Int. J. Civ. Eng., 2018, 17(5), 619628.

3. Webster, F. V., Traffic signal settings. RRL - Technical Paper No. 39, Her Majesty's A Stationary Office (HMSO), London, UK, 1958.

4. Highway Capacity Manual, Transportation Research Board, National Research Council, Washington, DC, USA, 2010.

5. IRC-SP, 41:1994. Guidelines for the design of at-grade intersections in rural and urban areas. Indian Roads Congress, New Delhi, 1994

6. Indian Highway Capacity Manual, CSIR Central Road Research Institute, New Delhi, 2018.

7. Hadiuzzaman, M., Rahman, M. and Karim, M. A., Saturation flow model at signalized intersection for non-lane based traffic. Can. J. Transp., 2008, 2(1), 77-90.
8. Shao, C. Q. and Liu, X. M., Estimation of saturation flow rates at signalized intersections. Discrete Dyn. Nature Soc., 2012, 1-9; doi:10.1155/2012/720474.

9. Australian Road Research Board, Australian Road Capacity Guide, Provisional Introduction and Signalized Intersection, ARRB Bulletin No. 4, 1968.

10. Indonesian Highway Capacity Manual, Urban and semi-urban traffic facilities. No. 09/T/BNKT/1993, Directorate General of Highways, Ministry of Public Works, Government of Indonesia, 1993.

11. Capacity and level of service of Finnish signalized intersections, S 12 solutions to improve main roads. Finnra Reports, 25/2002, Finnish Road Administration.

12. Malaysian Highway Capacity Manual, Ministry of Works Malaysia, 2006.

13. Taiwan Highway Capacity Manual, Institute of Transportation Report No. 100-132-1299, Ministry of Transportation and Communication, Taiwan, 2011.

14. FGSV (editor), 2015, Handbuch für die Bemessung von Straßenverkehrsanlagen (HBS), Edition 2015, German Highway Capacity Manual, Forschungsgesellschaft für Straßen- und Verkehrswesen (FGSV) (Road and Transport Association), Cologne, 2015.

15. Sarna, A. C. and Malhotra, S. K., Study of saturation flow at traffic light controlled intersection. Road Research Paper, 86, Central Road Research Institute, 1967.

16. Miller, A. J., The capacity of signalized intersections in Australia. Australian Road Research Board, Bulletin No. 3, 1968.

17. Bhattacharya, P. G. and Bhattacharya, A. K., Observation and analysis of saturation flow through signalized intersection in Calcutta. Indian Highways, 1982, 10(4), 11-33.

18. Potts, I. B., Harwood, D. W., Bauer, K. M., Gilmore, D. K., Ringert, J. F. and Zegeer, J. D., Relationship of lane width to saturation flow rate on urban and suburban signalized intersection approaches. In Proceedings of the 86th Annual Meeting of Transportation Research Board (CD-ROM), Washington DC, 2007.

19. Shao, C. Q., Rong, J. and Liu, X. M., Study on the saturation flow rate and its influence factors at signalized intersections in China. Proc. Soc. Behav. Sci., 2011, 16, 504-514; doi:10.1016/ j.sbspro.2011.04.471.

20. Susilo, B. H. and Solihin, Y., Modification of saturation flow formula by width of road approach. Proc. Soc. Behav. Sci., 2011, 16, 620-629; doi:10.1016/j.sbspro.2011.04.482.

21. Le, X., Lu, J. J., Mierzejewski, E. A. and Zhou, Y., Variations in capacity at signalized intersections with different area types. Transp. Res. Rec., J. Transp. Res. Board, 2000, 1710, 199-204; doi:10.3141/1710-23.

22. Bester, C. J. and Meyers, W. L., Saturation flow rates. In Proceedings of the 26th Southern African Transport Conference (SATC 2007), Pretoria, South Africa, 2007, pp. 560-568.

23. Hurley, J. W., Utilization of auxiliary through lanes at signalized intersections with downstream lane reductions. Transp. Res. Rec., J. Transp. Res. Board, 1997, 1572, 167-173; doi:10.3141/157220.

24. Chen, P., Nakamura, H. and Asano, M., Saturation flow rate analysis for shared left-turn lane at signalized intersections in Japan. Proc. Social Behav. Sci., 2011, 16, 548-559; doi:10.1016/ j.sbspro.2011.04.475.

25. Zhao, J., Yun, M. and Yang, X., Capacity model for signalized intersection under the impact of upstream short lane. Proc. Soc. Behav. Sci., 2013, 96, 1745-1754; doi:10.1016/j.sbspro. 2013.08.199.

26. Shang, H., Zhang, Y. and Fan, L., 'Heterogeneous lanes' saturation flow rates at signalized intersections. Proc. Soc. Behav. Sci., 2014, 138, 3-10; doi:10.1016/j.sbspro.2014.07.175.

27. Bargegol, I., Amlashi, A. T. and Gilani, V. N. M., Estimation the saturation flow rate at far-side and nearside legs of signalized 
intersections - case study, Rasht City. Proc. Eng., 2016, 161, 226-234; doi:10.1016/j.proeng.2016.08.539.

28. Liu, P., Lu, J. J., Fan, J., Pernia, J. C. and Sokolow, G., Effects of U-turns on capacities of signalized intersections. Transp. Res. Rec., J. Transp. Res. Board, 2005, 1920, 74-80; doi:10.1177/ 0361198105192000109.

29. Dehghani-Zadeh, M. and Tafti, M. F., Estimating saturation flow under weak discipline traffic conditions - case study, Iran. Arch. Transp., 2018, 46(2), 47-60.

30. Mondal, S., Arya, V. K. and Gupta, A., An optimized approach for saturation flow estimation of signalized intersections. Proc. Inst. Civ. Eng. - Transp., 2019; doi:10.1680/jtran.18. 00206 .

31. Minh, C. C. and Sano, K., Analysis of motorcycle effects to saturation flow rate at signalized intersection in developing countries. J. East. Asia Soc. Transp. Stud., 2003, 5, 1211-1212.

32. Vien, L. L., Ibrahim, W. H. W. and Mohd, A. F., Effect of motorcycle travel behaviour on saturation flow rates at signalized intersections in Malaysia. In 23rd ARRB Conference - Research Partnering with Practitioners, Adelaide, Australia, 2008.

33. Lila, W. K., Wicaksono, A. and Anwar, M. R., Analysis of motorcycle effects to saturation flow rate at signalized intersections in Malang City. J. Rekayasa Sipil, 2013, 7(3), 185-192.

34. Adams, C. A., Zambang, M. A. M. and Opoku-Boahen, R., Effects of motorcycles on saturation flow rates of mixed traffic at signalized intersections in Ghana. Int. J. Traffic Transp. Eng., 2015, 4(3), 94-101.

35. Davoodi, S. R., Sadeghiyan, S. and Faezi, S. F., The analysis the role of motorcycles on saturation flow rates at signalized intersections in Gorgan. Indian J. Sci. Technol., 2015, 8(13); doi:10.17485/ijst/2015/v8i13/52915.

36. Kockelman, K. M. and Shabih, R. A., Effect of light-duty trucks on the capacity of signalized intersections. J. Transp. Eng., $A S C E, \quad 2000, \quad \mathbf{1 2 6}(6), \quad 506-512$; doi:10.1061/(ASCE)0733947X(2000)126,6(506).

37. Lewis, E. and Benekohal, R., Saturation flow rate study at signalized intersections in Panama. In Proceedings of the 86th Annual Meeting of Transportation Research Board (CD-ROM), Washington DC, 2007.

38. Obiri-Yeboah, A., Amoah, A. S. and Acquah, P. C., Effect of trotros on saturation flow at selected signalized intersections on the 24th February Road, Kumasi, Ghana. Am. J. Eng. Res., 2013, 2(12), 235-243.

39. Tuffour, Y. A., Obiri-Yeboah, A. A., Saliful, M. and Acquah, P. C., Adjusting for the effect of bus blockage on saturation flows. Int. J. Sci. Res., 2014, 3(6), 749-753.

40. Yao, J., Xu, J. and Zhao, J., Effect of near-side on-line bus stop on signalized intersection capacity. Int. J. Control Autom., 2015, 8(12), 393-402; doi:10.14257/ijca.2015.8.12.36.

41. Behbahani, H., Samet, M. J., Gilani, V. N. M. and Amini, A., Determining of the parking manoeuvre and the taxi blockage adjustment factor for the saturation flow rate at the outlet legs of signalized intersections, case study from Rasht City (Iran). IOP Conf. Ser., Mater. Sci. Eng., 2017, 245(4), doi:10.1088/1757899X/245/4/042017.

42. Allen, D. P., Hummer, J. E., Rouphail, N. M. and Milazzo Ii, J. S., Effect of bicycles on capacity of signalized intersections. Transp. Res. Rec., J. Transp. Res. Board, 1998, 1646, 87-95; doi:10.3141/1646-11.

43. Milazzo II, J. S., Rouphail, N. M., Hummer, J. E. and Allen, D. P., Effect of pedestrians on capacity of signalized intersections. Transp. Res. Rec., J. Transp. Res. Board, 1998, 1646, 37-46; doi:10.3141/1646-05.

44. Cao, J. and Menendez, M., Generalized effects of on-street parking manoeuvres on the performance of nearby signalized intersections. Transp. Res. Rec., J. Trans. Res. Board, 2015, 2483(1), 30-38; doi:10.3141/2483-04.
45. Ibrahim, M. R., Karim, M. R. and Kidwai, F. A., The effect of digital countdown display on signalized junction performance. Am. J. Appl. Sci., 2008, 5, 479-482; doi:10.3844/ajassp.2008. 479.482.

46. Raksuntorn, W., The effects of countdown signals on intersection capacity. Int. Trans. J. Eng., Manage. Appl. Sci. Technol., 2012, 3(2), 159-165.

47. Sharma, A., Vanajakshi, L. and Rao, N., Effect of phase countdown timers on queue discharge characteristics under heterogeneous traffic conditions. Transp. Res. Rec., J. Transp. Res. Board, 2012, 2130, 93-100.

48. Devalla, J., Biswas, S. and Ghosh, I., The effect of countdown timer on the approach speed at signalized intersections. Proc. Comput. Sci., 2015, 52, 920-925; doi:10.1016/j.procs.2015. 05.166 .

49. Amison, S. J. A., Sadek, A. W. and El Dessouki, W., Inclement weather and traffic flow at signalized intersections, case study from northern New England. Transp. Res. Rec., J. Transp. Res. Board, 2004, 1867, 163-171; doi:10.3141/1867-19.

50. Chodur, J., Ostrowski, K. and Tracz, M., Impact of saturation flow changes on performance of traffic lanes at signalised intersections. Proc. Soc. Behav. Sci., 2011, 16, 600-611; doi:10.1016/ j.sbspro.2011.04.480.

51. Asamer, J. and Zuylen, H. J. V., Saturation flow under adverse weather conditions. Transp. Res. Rec., J. Transp. Res. Board, 2011, 2258, 103-109; doi:10.3141/2258-13.

52. Lu, Z., Fu, L. and Kwon, T. J., Effects of winter weather on traffic operations and optimization of signalized intersection. In Proceedings of the 96th Annual Meeting Transportation Research Board (CD-ROM), Washington DC, 2016.

53. Chen, P., Qi, H. and Sun, J., Investigation of saturation flow on shared right-turn lane at signalised intersections. Transp. Res. Rec., J. Transp. Res. Board, 2014, 2461, 66-75.

54. Webster, F. V. and Cobbe, B. M., Traffic signal. Ministry of Transport, Road Research Technical Paper No. 56, Govt of Japan, 1966.

55. Niittymaki, J. and Pursula, M., Saturation flows at signal-groupcontrolled traffic signal. Transp. Res. Rec., J. Transp. Res. Board, 1997, 1572, 24-32.

56. Li, H. and Prevedouros, P., Detailed observations of saturation headways and start-up lost times. Transp. Res. Rec., J. Transp. Res. Board, 2006, 1802, 44-53; doi:10.3141/1802-06.

57. Greenshields, B. D., Shapiro, D. and Erickson, E. L., Traffic performance at urban intersections. Bureau of Highway Traffic, Technical Report No. 1, Yale University, New Haven, Conn., USA, 1947.

58. Mondal, S. and Gupta, A., Assessment of vehicles headway during queue dissipation at signal controlled intersection under mixed traffic. Curr. Sci., 2019, 116(3), 437-444.

59. Chen, X. M., Shao, C. and Hao, Y., Influence of pedestrian traffic on capacity of right-turning movements at signalised intersections. Transp. Res. Rec., J. Trans. Res. Board, 2008, 2073, $11-124$.

60. Anusha, C. S., Verma, A. and Kavitha, G., Effects of twowheelers on saturation flow at signalised intersections in developing countries. J. Transp. Eng., 2013, 139(5), 448-457.

61. Kimber, R. M., McDonald, M. and Hounsell, N., Passenger car units in saturation flows, concept, definition, derivation. Transp. Res. Part B, Methodol., 1986, 19(1), 39-61; doi:10.1016/01912615(85)90028-1.

62. Williams, J. E. and Griffiths, J. D., The geometrical design of signalised road traffic junctions. In Proceedings of the 19th Conference on Winter Simulation, Atlanta, USA, 1987, 819-827.

63. Turner, J. and Harahap, G., Simplified saturation flow data collection methods. In CODATU VI Conference on the Development and Planning of Urban Transport, Tunis, February 1993, $1-15$. 
64. Branston, D. M. and Gipps, P., Some experience with a multiple linear regression method of estimating parameters of the traffic signal departure process. Transp. Res., 1981, 6, 445-458.

65. Chand, S., Gupta, N. J. and Velmurugan, S., Development of saturation flow model at signalized intersection for heterogeneous traffic. Transp. Res. Proc., 2017, 25, 1662-1671.

66. Perez-Cartagena, R. I. and Tarko, A. P., Calibration of capacity parameters for signalised intersections in Indiana. J. Transp. Eng., ASCE, 2005, 131(12), 904-911.

67. Raval, N. G., Gundaliya, P. J. and Rajpara, G., Development of relationship between saturation flow and capacity of mid-block section of urban road - a case study of Ahmedabad City. Int. J. Sci. Technol. Eng., 2017, 3(11), 313-318.

68. Rajgor, T. B., Patel, A. K. and Gundaliya, P. J., Development of saturation flow rate model for heterogeneous traffic at urban signalized intersections. Int. J. Innov. Res. Technol., 2016, 2(12), $151-155$

69. Radhakrishnan, P. and Mathew, T. V., Passenger car units and saturation flow models for highly heterogeneous traffic at urban signalised intersections. Transportmetrica, 2011, 7(2), 141-162; doi:10.1080/18128600903351001.

70. Saha, A., Chandra, S. and Ghosh, I., Saturation flow estimation at signalized intersections under mixed traffic conditions. Urban Transport, 2017, XXIII, 387-393.

71. Yadav, G. D. and Marsani, A., The effect of geometric factors on saturation flow at selected intersections of Kathmandu. Int. J. Res. Eng. Sci. Manage., 2019, 2(11), 131-136; doi:10.13140/ RG.2.2.31135.71843.

72. Ramireddy, S., Sala, E. and Ravishankar, K. V. R., Effect of encroaching vehicles on saturation flow at signalized intersections in mixed traffic conditions. J. Inst. Eng. (India), Ser. A, 2020, 1-7; doi:10.1007/s40030-019-00425-4.

73. Majhi, R. C., Field saturation flow measurement using dynamic passenger car unit under mixed traffic condition. Int. J. Traffic Transp. Eng., 2017, 7(4), 475-486.

74. Hellinga, B., Requirements for the validation and calibration of traffic simulation models. Proc. Can. Soc. Civ. Eng., 1998, I, 211-222.

75. Dowling, R., Skabardonis, A., Halkias, J., McHale, G. and Zammit, G., Guidelines for calibration of microsimulation models, framework and applications. Transp. Res. Rec., J. Transp. Res. Board, 2004, 1876(1), 1-9.

76. Cohen, S. L., An approach to calibration and validation of traffic simulation models. In 83rd Annual Meeting of the Transportation Research Board, Washington, DC, USA, 2004.

77. Arasan, V. T. and Vedagiri, P., Estimation of saturation flow of heterogeneous traffic using computer simulation. In Proceedings of the 20th European Conference on Modelling and Simulation, Bonn, Sankt Augustin, Germany, 2006, pp. 393-398.

78. Hossain, M., Estimation of saturation flow at signalized intersections of developing cities, a micro-simulation modelling approach. Transp. Res. Part A, 2001, 35, 123-141.

79. Tian, Z. Z., Urbanik, T. II, Engelbrecht, R. and Balke, K., Variations in capacity and delay estimates from microscopic traffic simulation models. Transp. Res. Rec., J. Trans. Res. Board, 2002 1802, 23-31; doi:10.3141/1802-04.

80. Kim, S., Kim, W. and Rilett, L. R., Calibration of microsimulation models using nonparametric statistical techniques. In Proceedings of 84th Annual Meeting of Transportation Research Board (CD-ROM), Washington DC, 2005.

81. Park, B., Won, J. and Yun, I., Application of microscopic simulation model calibration and validation procedure: case study of coordinated actuated signal system. Transp. Res. Rec., J. Transp. Res. Board, 2006, 1978, 113-122; doi:10.1177/ 0361198106197800115.

82. Arasan, V. T. and Koshy, R. Z., Methodology for modelling highly heterogeneous traffic flow. J. Transp. Eng., ASCE, 2005,
131(7), 544-551; doi:10.1061/(ASCE)0733-947X(2005)131, $7(544)$.

83. Chaudhry, M. S. and Ranjitkar, P., Capacity analysis of signalised intersection using micro-simulation. In 32nd Australian Transport Research Forum, Auckland, New Zealand, 2009.

84. Park, B. and Schneeberger, J. D., Microscopic simulation model calibration and validation, a case study of VISSIM for a coordinated actuated signal system. Transp. Res. Rec., J. Transp. Res. Board, 2003, 1856, 185-192.

85. Toledo, T. et al., Calibration and validation of microscopic traffic simulation tools, Stockholm case study. Trans. Res. Rec., J. Transp. Res. Board, 2003, 1831, 65-75.

86. Zhang, Y. and Owen, L. E., Systematic validation of a microscopic traffic simulation program. Transp. Res. Rec., J. Transp. Res. Board, 2004, 1876(1), 112-120.

87. Park, B. and Qi, H., Development and evaluation of a procedure for the calibration of simulation models. Transp. Res. Rec., J. Transp. Res. Board, 2005, 1934(1), 208-217.

88. Kim, K. O. and Rilett, L. R., A genetic algorithm based approach to traffic micro-simulation calibration using its data. In 83rd Annual Meeting of the Transportation Research Board, Washington, DC, USA, 2004.

89. Weinan, H. and Jian, S., A NGSA-II based parameter calibration algorithm for traffic microsimulation model. In International Conference Measuring Technology Mechatronics Automation, Zhangjiajie, China, 2009, vol. 3, pp. 436-439.

90. Mathew, T. V. and Radhakrishnan, P., Calibration of microsimulation models for nonlane-based heterogeneous traffic at signalized intersections. J. Urban Plann. Develop., 2010, 136(1), 5966.

91. Schultz, G. G. and Rilett, L. R., Calibration of distributions of commercial motor vehicles in CORSIM. Transp. Res. Rec., J. Transp. Res. Board, 2005, 1934(1), 246-255.

92. Cunto, F. and Saccomanno, F. F., Calibration and validation of simulated vehicle safety performance at signalized intersections. Accident Anal. Prev., 2008, 40(3), 1171-1179.

93. Manjunatha, P., Vortisch, P. and Mathew, T. V., Methodology for the calibration of vissim in mixed traffic. In 83rd Annual Meeting of Transportation Research Board, Washington, DC, USA, 2013.

94. Maheshwary, P., Bhattacharyya, K., Maitra, B. and Boltze, M., A methodology for calibration of traffic micro-simulator for urban heterogeneous traffic operations. J. Traffic Transp. Eng. (English edition), 2019.

95. Fang, F. C. and Elefteriadou, L., Some guidelines for selecting microsimulation models for interchange traffic operational analysis. J. Transp. Eng., 2005, 131(7), 535-543.

96. Gundaliya, P. J., Mathew, T. V. and Dhingra, S. L., Heterogeneous traffic flow modelling for an arterial using grid based approach. J. Adv. Transp., 2008, 42(4), 467-491.

97. Mohan, M. and Chandra, S., Queue clearance rate method for estimating passenger car equivalents at signalized intersections. J. Traffic Transp. Eng., 2017, 4(5), 487-495.

98. Biswas, S., Chakraborty, S., Ghosh, I. and Chandra, S., Saturation flow model for signalized intersection under mixed traffic condition. Transp. Res. Rec., J. Transp. Res. Board, 2018, 2672(15), 55-65.

99. Saha, A., Chakraborty, S., Chandra, S. and Ghosh, I., Kriging based saturation flow models for traffic conditions in Indian cities. Transp. Res. Part A, 2018, 118, 38-51.

100. Wu, N., Capacity at all-way stop-controlled and first-in-first-out intersection. In 4th International Symposium on Highway Capacity Proceedings, Maui, Hawaii, 2000.

101. Li, H., Tian, Z. and Deng, W., Capacity of multilane all-way stop-controlled intersections based on the conflict technique. Transp. Res. Rec., J. Transp. Res. Board, 2011, 2257, 111120. 
102. Solberg, P. and Oppenlander, J. C., Lag and gap acceptances at stop controlled intersections. Highway Res. Rec., 1966, 118, 48-67.

103. Sinha, K. C. and Tomiak, W. W., Section gap acceptance phenomenon at stop-controlled intersections. Transp. Res. Rec., J. Transp. Res. Board, 1971, 41(7), 28-33.

104. Radwan, A. E. and Sinha, K. C., Gap acceptance and delay at stop controlled intersections on multilane divided highways. J. Inst. Transp. Eng., 1980, 50(3), 38-44.

105. Fitzpatrick, K., Gaps accepted at stop-controlled intersections. Transp. Res. Rec., J. Transp. Res. Board, 1991, 1303, 103112.

106. Gattis, J. L. and Low, S. T., Gap acceptance at a typical stopcontrolled intersections. J. Transp. Eng., ASCE, 1999, 116(2), 153-166.

107. Preethi, P. and Ashalatha, R., Estimation of saturation flow under heterogeneous traffic conditions. Proc. Inst. Civ. Eng.-Transport, 2019, 172(1), 1-11.

108. Hung, W. T., Tian, F. and Tong, H. Y., Discharge headway at signalized intersections in Hong Kong. J. Adv. Transp., 2002, 37(1), 105-117.

109. Joseph, J. and Chang, G. L., Saturation flow rates and maximum critical lane volumes for planning applications in Maryland. J. Transp. Eng., 2005, 131(12), 946-952.

110. Long, G., Driver behavior model of saturation flow. Transp. Res. Rec., J. Transp. Res. Board, 2007, 2027(1), 65-72.

111. Schoepflin, T. N. and Dailey, D. J., Algorithms for calibrating roadside traffic cameras and estimating mean vehicle speed. In Proceedings of the IEEE Intelligent Transportation Systems Conference, Washington DC, 2004, pp. 60-65.

112. Chopade, K. and Guru, S., A survey, unmanned aerial vehicle for road detection and tracking. Int. J. Innov. Res. Comput. Commun. Eng., 2015, 3(10), 10761-10766.
113. Mondal, S. and Gupta, A., Modeling driver acceleration behaviour at signalized intersection under mixed traffic environment. J. Eastern Asia Soc. Transp. Stud., 2019, 13, 1761-1776.

114. Yu, X., Sulijoadikusumo, G., Li, H. and Prevedouros, P., Reliability of automatic traffic monitoring with non-intrusive sensors. In ICCTP 2011: Towards Sustainable Transportation Systems, Nanjing, China, 2011, pp. 4157-4169.

115. Ali, S. S. M., George, B., Vanajakshi, L. and Venkatraman, J., A multiple inductive loop vehicle detection system for heterogeneous and lane-less traffic. IEEE Trans. Instrumen. Measure., 2012, 61(5), 1353-1360.

116. Rahman, M., Nur-Ud-Deen, S. and Hassan, T., Comparison of saturation flow rate at signalized intersections in Yokohama and Dhaka. Proc. East. Asia Soc. Transp. Stud., 2005, 5, 959-966.

117. Hussain, A. M., Determination of saturation flows at signalised intersections in Malaysian Urban Areas. In 6th REAAA Conference Proceedings, Kuala Lumpur, 2, 1990.

118. Huzayyin, A. S. and Shoukry, W. S., Saturation flow and effective approach width at signalised intersections in Greater Cairo. IN 6th African Highway IRF Conference, Geneva, 1986.

119. Branston, D., Some factors affecting the capacity of signalized intersections. Traffic Eng. Control, 1979, 20, 390-396.

120. Highway Engineering Laboratory, Improvements to advanced modelling techniques for traffic engineering applications in the European community. Report 1. National Technical University of Athens, Greece, 1990.

121. Austroads, Guide to Traffic Engineering Practice, National Association of Australian State Road Authorities, 1988.

Received 28 May 2019; revised accepted 4 May 2020

doi: $10.18520 / \mathrm{cs} / \mathrm{v} 119 / \mathrm{i} 1 / 32-43$ 